\title{
Gulf Cooperation Council Monetary Union: Business Cycle Synchronization, Shocks Correlation
}

\author{
Nabil Ben Arfa, CEMAFI, University of Nice Sophia-Antipolis, France
}

\begin{abstract}
In this paper we assess the readiness of the Gulf cooperation council members (Qatar, Saudi Arabia, Kuwait and Bahrain) to form a viable currency monetary area. It deals with business cycle synchronization and economic shocks correlation. To do so we employ different methods, first we extract the business cycle component of output using Hodrick-Prescott filter. Second, supply and demand shocks are recovered from an estimated structural VAR model of output growth and inflation using long run restriction (Blanchard and Quah). We then check the (A) symmetry of these shocks by calculating the correlation between GCC countries.

It's appears from our investigation that there is no business cycle synchronization evidence between GCC countries, business cycle is rather divergent among them. And despite of the demand shocks symmetry, supply shocks are rather asymmetric. We therefore conclude that there is no evidence of the readiness of the GCC members to form a monetary currency union
\end{abstract}

Keywords: Golf Cooperation Council Countries; SVAR Models; Hodrick-Prescott Filter; Business Cycle; Symmetric-Asymmetric Shocks; GCC Monetary Union

\section{INTRODUCTION}

$\mathrm{n}$ this paper we attempt to evaluate the correlation of business cycles within the Gulf Cooperation
Council countries (Qatar, Saudi Arabia, Kuwait and Bahrain). We want to assess whether these countries
are confronted to symmetrical shocks (if an area, a zone or a country are hit by similar shocks) or rather asymmetrical (if the shocks and/or their impacts are not similar).

Investigation on the nature of business cycles and shocks correlation within GCC countries leads us to the optimal currency areas theory.

The main contributions on optimal currency areas theory are those of Mundell (1961), followed by Mckinnon (1963) and Kenen (1969), which were considered as the base to later studies. Their objective was to identify the main criteria of a possible integration of a country to a monetary area. The method consists in identifying benefits and costs which a given country can carry out by joining the monetary area. If benefits for each country wishing integration are positive and higher than costs, monetary area is called as optimal.

Our paper is placed in this context; we want to check whether GCC countries can form an optimal currency area. To answer this, we will consider the way business cycles evolve in these countries. The purpose is to asses if a synchronization of business cycles between them does really exist, because a better synchronization means that GCC countries become increasingly convergent, and thus a loss of monetary instrument does not constitute a danger to the economy. To conduct this comparative analysis of business cycles, we will use Hodrick-Presscott filtering method.

\footnotetext{
1 Yemen and UAE are not included.
} 
Thereafter, to improve our results, and to clarify synchronization or differences in business cycles evolution found before, we estimate a structural VAR model (SVAR), in order to discover supply and demand shocks affecting countries, and especially to verify whether these countries are affected by symmetric or asymmetric shocks which is essential in determination of the optimality of the GCC area.

The methodology suggested by Bayoumi and Einchengreen (1992), placed in the line of Blanchard and Quah work, constitutes our base of work. Indeed, the principal assumption of their model is there were two kinds of shocks: shocks affecting the demand curve (for example those due to monetary policy changes) and shocks affecting supply curve (like technological changes). As for Blanchard and Quah model, it is clear that demand and supply shocks have different effects on output and prices. If supply shocks have permanent effects on production, demand shocks have only temporary one; on the other hand the two shocks have permanent effects on price.

One then can be able to introduce these assumptions into a structural VAR model whose variables are production and prices in order to check supply and demand shocks, and their effects on economic variables (through impulse response function and variance decomposition). Finally this paper will be ended by mentioning results and declaring recommendations.

\section{PREVIOUS EMPIRICAL STUDIES ON GCC MONETARY UNION}

There are few studies on monetary union issue between GCC countries, these studies typically look at the feasibility of monetary union from a viewpoint of costs and benefits for each country. The majority of studies concluded that GCC countries are not ready to abolish their national currencies and adopt a common currency.

An early attempt to examine the readiness of the GCC to form a currency union was made by Zaidi (1990). He observed convergence in inflation rates and moderate dispersion in the growth rates of broad money. Furthermore, he found that the responsiveness of output to unanticipated money growth, and thus the inflationunemployment tradeoffs, vary greatly among GCC members. To avoid serious consequences of the observed variations, Zaidi (1990) suggested extensive coordination of monetary policies.

Dar and Presley (2001) pointed out the low level of integration among GCC members as illustrated by the insignificant volume of intra-regional trade. They attributed this fact to the similarity of oil-based economic structures and to economic and political factors. The authors recommended introducing more flexible rules for intraregional trade and Foreigner direct investment, enhancing the production diversification process, accelerating privatization efforts, and increasing Saudi Arabia's trade with GCC members instead of trading outside the region.

Laabas and Limam (2002) provided another evaluation of the readiness of GCC countries to establish a monetary union. They used a formal test based on the generalized purchasing power parity. They found that the GCC countries have not yet met the pre-requirements to establish a monetary union due to the fact that the GCC economies are oil-dependent, have little intra-trade, lack convergence in macroeconomic fundamentals, and lack synchronization in business cycles. In contrast, the authors mentioned that the GCC countries are more likely to satisfy the monetary union criteria ex-post rather than ex-ante.

Establishing a monetary union may align the business cycles to increase intra-trade among the GCC countries. The authors claimed that in order to accelerate the progress towards the monetary union, restrictions on factors mobility have to be eliminated in addition to more political unification.

A similar examination of the readiness of GCC countries for a common currency was carried out by Jadresic (2002). He weighed the possible benefits and costs incurred as a result of replacing individual GCC currencies with a common regional currency and concluded that the success of such a union is conditional on a broader set of measures including the removal of domestic and cross-border distortions that prevent trade and foreign investments, coordinating policies that ensure macroeconomic stability, and enhancing the process of political integration. 
Shotar and Shams (2005) examined the economic structure of the GCC countries to find whether or not the GCC members can adopt similar policies when launching the common currency in 2010. They found that the GCC countries follow different economic policies, and significant differences exist that may limit the expected benefits of the monetary union.

By testing for co-integration among the GCC countries' GDPs, inflation rates, exchange rates, and monetary bases, Darrat and Al-Shamsi (2005) reached the conclusion that the GCC countries are compatible to establish a monetary union. Nonetheless, the failure in doing so is due to socio-political factors that have hampered the process towards the monetary union. Hebous (2006) concluded that the reduction of the costs of forming a monetary union in the GCC case is due to the similarities among the GCC economies. He also called attention to the notable degree of convergence that the GCC countries have achieved in terms of the convergence criteria.

A study by Abu-Bader and Abu-Qarn (2006), which is the much closer to ours, concluded that the GCC countries are not yet ready to establish a monetary union. The authors used three different methods to test the GCC economies. The first method was the Structural VAR to identify both demand and supply shocks and to find whether these shocks are symmetric or not. The second method was the co-integration tests to find whether long-term relationships of real GDP among all the possible paired countries exist. The last method was to find whether there are common business cycles among the GCC countries. All three methods provide no support for establishing a monetary union.

A recent study by Louis, Rosmy, Balli and Mohammad (2008) tested whether the GCC countries are subject to symmetric aggregate demand (AD) and non-oil aggregate supply (AS) shocks. The authors also tested the suitability of the Euro as a common anchor on the basis of shocks asymmetry between three major European countries (France, Germany, and Italy) and the GCC countries. They concluded that AD shocks are clearly symmetrical but non-oil AS shocks are weakly symmetrical across the GCC countries, which supports the monetary union. Authors found that neither AD nor AS shocks are symmetrical between the GCC countries and the selected European countries. One more result was found is that GCC's AD shocks are symmetrical with the US but non-oil AS shocks are not. This finding supports using the US dollar as a common anchor for the GCC countries since US monetary policy can help smooth demand shocks in the GCC countries.

\section{BUSINESS CYCLES SYNCHRONIZATION WITHIN GULF COOPERATION COUNCIL (GCC) COUNTRIES: CORRELATION OF GDP}

In order to test if countries chosen for our analysis are affected by common fluctuations, it is possible relating on the cyclical behaviour of economic aggregates, GDP in particular, to evaluate how these countries evolve through time. Business cycles synchronization is therefore regarded as a sign of convergence between them and a monetary union is possible.

Economies tend to fluctuate around a long term trend. Fluctuations around this trend correspond to the cyclical fluctuations. One of the most used methods in the literature to assess business cycles is the Hodrick-Prescott technique of decomposition (1980). Based on this method we try to determine the connection of business cycle between the GCC countries, results drawing from this analysis teach us about optimality (or not) of a potential monetary union.

Data employed in our analysis are annual data, extracted from the United Nations Statistics Division (National Accounts Main aggregate database). After filtering the data and their decomposition into trend components-cyclical components according to HP method (Hodrick-Prescott), we make comparisons between the cyclical components of the different countries.

Results are showed in the table below. 
Table 1: Business cycle correlation among GCC countries

\begin{tabular}{|l|c|c|c|c|}
\hline & Kuwait & Qatar & Saudi Arabia & Bahrain \\
\hline Kuwait & 1 & & & \\
\hline Qatar & 0.053249 & 1 & & \\
\hline Saudi Arabia & -0.041900 & 0.199283 & 1 & \\
\hline Bahrain & $0.333711^{*}$ & $0.302355^{*}$ & $0.582465^{*}$ & 1 \\
\hline
\end{tabular}

Source: our estimations

* Significant at $5 \%$

Results indicate that all countries have a positive business cycle correlation except for correlation between Kuwait and Saudi Arabia which is negative and equal to -0.04 . We also find that these correlations are significant only in three cases, all related to Bahrain.

Bahrain's business cycle seems to be correlated with the business cycle of the countries panel (Kuwait, Qatar and Saudi Arabia).

So the table above shows that there is no business cycle synchronization between the most studied countries. Business cycle is rather divergent among GCC countries.

In the following section, we use a different method in order to verify cyclical tendencies results found before. Our purpose is to assess the cyclical fluctuations sources, in other words we will identify the sources of disturbances, and the economic policies responses to these shocks.

\section{STRUCTURAL VAR MODEL: (A) SYMMETRY OF DEMAND AND SUPPLY SHOCKS}

In order to check if differences observed in cyclical tendencies between GCC countries come from shocks differences or from economic policies responses to these shocks, an alternative econometric method will be applied in this section. It is the structural VAR methodology which main objective is to identify shocks, their nature (symmetrical or asymmetrical) and economic aggregates response to these disturbances.

First, we expose the model of Bayoumi and Eichengreen (1992), which is considered in this context as a standard. We then apply this structural VAR methodology to the GCC countries.

\subsection{Model of Bayoumi and Eichengreen (1992)}

This influential contribution falls in a large empirical literature whose objective is to test the validity of the optimal currency areas theory. Its starting point is the fact that an economy can be hit either by demand shocks or by supply shocks. Demand and supply shocks are identified by using restrictions on the long run impact of demand shocks on production.

Indeed, demand shocks are supposed to have zero effect on the long-term production, only supply shocks are supposed to have permanent effect on output.

After identifying the nature and the effects of the various shocks on economy, Bayoumi and Eichengreen estimate a VAR model on GNP and price of European Community (the Twelve minus Luxembourg). In order to transform the residuals of each estimated VAR into demand and supply shock, they apply the decomposition procedure of Blanchard and Quah (1989). This procedure makes possible the distinction between temporary and permanent shocks. Shocks correlation calculated between countries provide information on the degree of the asymmetry of real shocks, while impulse response functions associated to structural VAR make possible the evaluation of the speed adjustment of each economy to these various shocks.

In order to evaluate the relative weight of these shocks, the same econometric procedure is applied to the United States. In addition, Europe and United States are divided into a "center" of countries or States, characterized by symmetrical behaviour, and a "periphery", in which shocks are less correlated with those of the center. 
The starting point of the model is the following:

$$
\left[\begin{array}{c}
\Delta Y_{t} \\
\Delta P_{t}
\end{array}\right]=\sum_{i=0}^{\infty}\left(\begin{array}{ll}
a_{11 i} & a_{12 i} \\
a_{21 i} & a_{22 i}
\end{array}\right) \cdot\left[\begin{array}{l}
e_{d t} \\
e_{s t}
\end{array}\right]
$$

Where $\Delta Y_{t}$ and $\Delta P_{t}$ respectively represent the logarithm of the GNP growth rate and that of prices in time $T, e_{d t}$ and $e_{s t}$ represent demand and supply shocks. Identifying constraints are based on the assumptions already mentioned, related to the nature of the effects of shocks on variables. As the product (output) is represented on first difference, the constraints on demand shocks imply that the cumulated effects of demand shocks must be equal to zero:

$$
\sum_{i=0}^{\infty} a_{11 i}=0
$$

The model defined by equations (1) and (2) also implies that endogenous variables of the VAR model can be explained by various lag variables. If we suppose that $B_{i}$ represent the coefficients values of the model, the model can be estimated as follows:

$$
\left[\begin{array}{c}
\Delta Y_{t} \\
\Delta P_{T}
\end{array}\right]=B_{1} \cdot\left[\begin{array}{l}
\Delta Y_{t-1} \\
\Delta P_{t-1}
\end{array}\right]+B_{2} \cdot\left[\begin{array}{l}
\Delta Y_{t-2} \\
\Delta P_{t-2}
\end{array}\right]+\ldots+\left[\begin{array}{l}
e_{y t} \\
e_{p t}
\end{array}\right]
$$

Or $e_{y t}$ and $e_{p t}$ are the residuals of the VAR model equations.

Equation (3) can also be expressed as:

$$
\left[\begin{array}{c}
\Delta Y_{t} \\
\Delta P_{t}
\end{array}\right]=\left(I-B(L)^{-1}\right) \cdot\left[\begin{array}{l}
e_{y t} \\
e_{p t}
\end{array}\right]=\left(I+B(L)+B(L)^{2}+\ldots\right) \cdot\left[\begin{array}{l}
e_{y t} \\
e_{P t}
\end{array}\right]
$$

Or in an equivalent way:

$$
\left[\begin{array}{l}
\Delta Y_{t} \\
\Delta P_{t}
\end{array}\right]=\sum_{i=0}^{\infty}\left(\begin{array}{ll}
d_{11 i} & d_{12 i} \\
d_{21 i} & d_{22 i}
\end{array}\right) \cdot\left[\begin{array}{l}
e_{y t} \\
e_{p t}
\end{array}\right]
$$

Let put (1) and (5) together:

$$
\sum_{i=0}^{\infty}\left(\begin{array}{ll}
d_{11 i} & d_{12 i} \\
d_{21 i} & d_{22 i}
\end{array}\right) \cdot\left[\begin{array}{l}
e_{y t} \\
e_{p t}
\end{array}\right]=\sum_{i=0}^{\infty} L^{i}\left(\begin{array}{ll}
a_{11 i} & a_{12 i} \\
a_{21 i} & a_{22 i}
\end{array}\right) \cdot\left[\begin{array}{l}
e_{d t} \\
e_{s t}
\end{array}\right]
$$

$C$, a matrix connecting demand and supply shocks of the VAR model to the residuals can thus be found.

$$
\left[\begin{array}{l}
e_{y t} \\
e_{p t}
\end{array}\right]=\left(\sum_{i=0}^{\infty}\left(\begin{array}{ll}
d_{11 i} & d_{12 i} \\
d_{21 i} & d_{22 i}
\end{array}\right)^{-1} \cdot \sum_{i=0}^{\infty} L^{i} \cdot\left(\begin{array}{ll}
a_{11 i} & a_{12 i} \\
a_{21 i} & a_{22 i}
\end{array}\right)\right) \cdot\left[\begin{array}{l}
e_{d t} \\
e_{s t}
\end{array}\right]=c \cdot\left[\begin{array}{l}
e_{d t} \\
e_{s t}
\end{array}\right]
$$


From equation (7), it is clear that in this model of order two, four restrictions are needed to identify the $C$ matrix elements. Two of these restrictions are drawn from the assumption of normality of the variance of shocks $e_{d t}$ and $e_{s t}$. A general assumption retained within the framework of VAR model consists in imposing that the two variances are equal to one. These two assumptions combined with that of orthogonality define the third restriction, $c^{\prime} c=S$, where $S$ represents the covariance matrix of $\mathrm{E}_{y}$ and $\mathrm{E}_{p}$.

The last restriction which will make the identification of the $C$ matrix possible comes from the economic theory; it was previously defined in equation (2).

Introducing (2) in (7) yields the following model:

$$
\sum_{i=0}^{\infty}\left(\begin{array}{ll}
d_{11 i} & d_{12 i} \\
d_{21 i} & d_{22 i}
\end{array}\right) \cdot\left(\begin{array}{ll}
c_{11} & c_{12} \\
c_{21} & c_{22}
\end{array}\right)=\left(\begin{array}{ll}
0 & . \\
. & .
\end{array}\right)
$$

And thus the resolution of this system will enable us to estimate the series of demand and supply shocks of the structural VAR model.

The analysis of Bayoumi and Eichengreen shows that supply shocks are larger and less correlated between countries (or areas) in Europe in comparison with the United States. In addition and through the impulses responses functions of the structural VAR model, they suggest that adjustment to supply shocks as well as to demand shocks is faster in the United States than in Europe.

Consequently, as the American monetary union constitutes a point of comparison, they consider that a possible EMU would be associated with significant adjustments costs.

Moreover, results of their model reveal the existence of a difference between two groups of Europe (the center and the periphery) with regard to supply shocks and to a lesser extent to demand shocks. Indeed, shocks affecting the economies of the center (Belgium, Denmark, France, Germany and Netherlands) are of less amplitude and more correlated with neighbours countries, while fluctuations in countries of the periphery seems to be asymmetrical ${ }^{2}$. In addition, the two authors suppose that there are a few results in favour of convergence, the difference between the center and the periphery do not decrease during the studied period.

In what follows, we apply this model to our sample of countries.

\subsection{Application to the GCC countries}

We have an economy whose growth rate and inflation rate are affected each year, $\mathrm{T}$, by two orders of shocks: supply impulses $\left(\varepsilon_{s t}\right)$ and demand impulses $\left(\varepsilon_{d t}\right)$. The model resolution is the same as in Bayoumi and Eichengreen model.

We estimate a Structural VAR model in first differences. Variable representing growth rate is the first difference of the logarithm of GDP ( $\left.\Delta Y_{t}\right)$, inflation rate is estimated through the logarithm of the GDP deflator in the first difference $\left(\Delta P_{t}\right)$.

\footnotetext{
${ }^{2}$ Notice that this method has certain drawbacks. First, the results may be influenced by the choice of anchor area (the center in Bayoumi and Eichengreen study). Second, this approach does not produce a decomposition of demand and supply shocks into their structural common and specific components, which makes it difficult to interpret the results concerning the correlation of shocks. In order to correct these deficiencies, recent methods propose to use a state-space model. The purpose of the state-space model is to decompose the structural shocks

(Demand and Supply shock) in each of the countries (the regions, the area...) into two unobservable stochastic components: one common and the other specific. The relative importance of the country-specific component can be interpreted as a measure of the degree of asymmetry.
} 
Data employed are annuals, extracted from the United Nations Statistics Division (National Accounts Main aggregate database). The studied period extends from 1970 to 2008; the data are related to Saudi Arabia, Kuwait, Bahrain, and Qatar.

\subsubsection{Study of variables stationnarity}

Table 2: ADF Unit Root Test Results

\begin{tabular}{|c|c|c|c|c|}
\hline \multirow[b]{2}{*}{ Real GDP } & \multicolumn{2}{|c|}{ Levels } & \multicolumn{2}{|c|}{ First Difference } \\
\hline & ADF & $\begin{array}{c}\text { T Value } \\
(p=5 \%)\end{array}$ & ADF & $\begin{array}{c}\text { T Value } \\
(p=5 \%)\end{array}$ \\
\hline Bahrain & 5.81 & -1.95 & $5.62 *$ & -2.89 \\
\hline Kuwait & 0.47 & -1.95 & -5.80 & -1.95 \\
\hline Qatar & 5.81 & -1.95 & $-4.69 *$ & -2.89 \\
\hline S. Arabia & $4.94 *$ & -2.89 & -2.91 & -1.95 \\
\hline \multirow[b]{2}{*}{ Deflator } & \multicolumn{2}{|c|}{ Levels } & \multicolumn{2}{|c|}{ First Difference } \\
\hline & ADF & $\begin{array}{c}\text { T Value } \\
(\mathbf{p}=5 \%)\end{array}$ & ADF & $\begin{array}{l}\text { T VALUE } \\
(p=5 \%)\end{array}$ \\
\hline Bahrain & $2.77^{*}$ & -2.89 & -2.65 & -1.95 \\
\hline Kuwait & $-2.81^{*}$ & -2.89 & -4.27 & -1.95 \\
\hline Qatar & 1.61 & -1.95 & -2.89 & -1.95 \\
\hline S. Arabia & 1.63 & -1.95 & -4.236601 & -1.95 \\
\hline
\end{tabular}

* Model with intercept.

All variables are integrated of order one as showed in the upper table, so we estimate a structural VAR model in first difference.

In all cases the VAR lag length introduced is four as indicated by information criteria. Thus identification diagram will be homogeneous for each country.

After the VAR estimation for each country, structural demand and supply shocks are identified. We attempt to check if these economic shocks are symmetrical or not and if the countries are able to form an optimal currency area. To reach this objective, after models estimation (for each country) and shocks identification, we carry out the correlation analysis of these shocks. Knowing that, a positive correlation is supposed to be a favourable criterion for the constitution of a monetary union ${ }^{3}$.

\subsubsection{Symmetry or Asymmetry of shocks}

Table 3: Correlation Coefficients of supply shocks

\begin{tabular}{|l|c|c|c|c|}
\hline & S. Arabia & Qatar & Kuwait & Bahrain \\
\hline S. Arabia & 1.000000 & & & \\
\hline Qatar & 0.180847 & 1.000000 & & \\
\hline Kuwait & -0.044386 & 0.300299 & 1.000000 & \\
\hline Bahrain & 0.362421 & 0.150389 & 0.231817 & 1.000000 \\
\hline
\end{tabular}

Source: our estimations

The table above represents the correlation coefficients values which measure the link between supply shocks in GCC countries.

Supply shocks are likely to reflect exogenous factors such as oil price shocks, productivity shock... Bayoumi and Eichengreen (1993) argue that supply shocks serve as better indicators of the symmetry or asymmetry of the underlying disturbances following a change in the exchange rate regime.

\footnotetext{
${ }^{3}$ Variance decomposition and impulse response functions for each model (each country) are available from the author.
} 
From the table we notice that, generally speaking, the contemporaneous supply shocks are asymmetric. The correlation coefficients are either negative (for Saudi Arabia and Kuwait) or positive but statistically insignificant in all instances.

Asymmetric supply shocks means that shocks or their impacts are not similar, so policy responses will differ across countries. And if those countries are members of a monetary union then the common monetary policy can't serve stabilization in all member countries simultaneously.

These asymmetric supply disturbances do not lend support to the establishment of a viable currency union among the GCC countries.

Table 4: Correlation Coefficients of demand shocks

\begin{tabular}{|l|c|c|c|c|}
\hline & S. Arabia & Qatar & Kuwait & Bahrain \\
\hline S. Arabia & 1.000000 & & & \\
\hline Qatar & 0.671009 & 1.000000 & & \\
\hline Kuwait & 0.759578 & 0.756369 & 1.000000 & \\
\hline Bahrain & 0.561008 & 0.470018 & 0.591282 & 1.000000 \\
\hline
\end{tabular}

Source: our estimations

In contrast to supply shocks, the correlation coefficients of demand shocks among countries are positive and highly significant in all cases. This finding indicates that contemporaneous demand shocks faced by the GCC countries, unlike supply shocks, are symmetric. This finding can be explained by the fact that GCC economies are dominated by public sector that boosts demand during episodes of high oil prices and reduces demand during episodes of low oil prices.

\section{SUMMARY}

We examine whether the member of the Gulf Cooperation Council countries (Qatar, Saudi Arabia, Kuwait and Bahrain) are ready to form a viable currency union applying different methods. First, based on Hodrick-Prescott technique of decomposition (1980), we test whether countries chosen are affected by common fluctuations. Relating in the cyclical behaviour of economic aggregate, GDP in this case, we evaluate how these countries move thought time and if there was business cycle synchronization.

We find that all countries have a positive business cycle correlation. However these positive correlations are significant only in the case of Bahrain which means that Bahrain business cycle is correlated with the business cycle of all the other countries. So, there is no business cycle synchronization evidence between GCC members, business cycle is rather divergent among them.

Second, we use an alternative econometric method, the structural VAR methodology to identify shocks, their nature and economic adjustment to them.

The methodology suggested by Bayoumi and Einchengreen (1992), placed in the line of Blanchard and Quah work, constitutes our base of work. Indeed, the principal assumption of their model is there were two kinds of shocks: shocks affecting the demand curve and shocks affecting supply curve. As for Blanchard and Quah model, it is clear that demand and supply shocks have different effects on output and prices. If supply shocks have permanent effects on production, demand shocks have only temporary one; on the other hand the two shocks have permanent effects on price.

We introduce these assumptions into a structural VAR model whose variables was production and prices in order to check supply and demand shocks, and their effects on economic variables through impulse response function and variance decomposition. 
We find that while supply shocks are asymmetric, negative correlation, demand shocks are symmetric. Since supply shocks are the product of external factors and not domestic policies, they constitute better indicators of the costs of forming a monetary union. Thus, lack of significant correlations lends no support for the readiness of the GCC countries to establish a viable currency union.

To sum up, method employed in here provide no evidence of business cycle and shocks correlation, so there is no evidence of the readiness of the GCC members to form an optimal currency monetary area. Despite of the demand shocks positive correlation, the monetary policies cooperation, more effort are needed to align financial, fiscal and political systems.

\section{AUTHOR INFORMATION}

Nabil Ben Arfa received a Ph.D., magna cum laude, in Economics, from University of Nice Sophia-Antipolis (France). Prior to that, he obtained a Master degree, summa cum laude, in Macroeconomics and International Finance (University of Nice too). He has also a Master degree in Monetary and Banking Economics from the University of Tunis.

During his studies, he acquired a high degree of expertise in theoretical and empirical Economics analysis. Therefore, his is proficient with econometrics models using Eviews / Stata, and with simulation models, like DSGE models, using Matlab.

Thesis research has been orientated to macroeconomics shocks, business cycle and policies in small open economies (France, Central and Eastern European countries). He has also a three year-teaching position at the University of Nice Sophia- Antipolis and two year position at the University of Angers. E-mail: nabil_ar@yahoo.fr

\section{REFERENCES}

1. Abu-Bader, S. and A. Abu-Qarn, On the Optimality of a GCC Monetary Union: Structural VAR, Common Trends and Common Cycles Evidence, The world economy, 31(5), pp.612-630, 2008.

2. Bayoumi, T. and B. Eichengreen, Growth and adjustment in the European Monetary Union, ed. New York, Cambridge University Press, pp.193-230, 1992.

3. Blanchard, O.J. and D. Quah, The Dynamic effects of Aggregate demand and Supply Disturbances, American Economic Review, 79(4), pp.655-673, 1989.

4. Dar, Humayon A., Presley, and R. John, The Gulf Co-operation Council: A Slow Path to Integration?, The World Economy, 24, pp.1161-1178, 2001.

5. Darrat, Ali F., Al Shamsi and S. Fatima, On the Path of Integration in the Gulf Region, Applied Economics, 37, pp.1055-1062, 2005.

6. Hebous, S., On the Monetary Union of the Gulf States, working paper 431, The Kiel Institute for the World Economy, 2006.

7. Hodrick, R. J. and E.C., Prescott, Post-war U.S. business cycles: An empirical Investigation, Discussion paper 451, Carnegie-Mellon University, 1980.

8. Jadresic, Esteban, On a Common Currency for the GCC Countries, IMF Policy Discussion Paper, 2002.

9. Kenen, P.B., Monetary Problems of the International Economy, eds. Chicago, University of Chicago press, pp.41-60, 1969.

10. Laabas, Belkacem and Imed Limam, Are GCC Countries Ready for Currency Union?”, Arab Planning Institute- Kuwait, 2002.

11. Louis, R., Balli and M. Osman, Monetary Union Among Arab Gulf Cooperation Council (AGCC) Countries: Does the symmetry of shocks extend to the non-oil sector?, Munich Personal RePEc Archive, 2008.

12. McKinnon, R., Optimum Currency Areas, American Economic Review, 53(4), pp.717-725, 1963

13. Mundell, R., A Theory of Optimum Currency Areas, American Economic Review, 51(4), pp.657-665, 1961.

14. Sarte, P.D., On the Identification of Structural Vector Auto regressions, Economic Quarterly, pp.45-68, Federal Reserve Bank of Richmond, 1997. 
15. Shotar, M. and S. Khalid, Economic Policies and the Possibilities of Unified GCC Currency, University of Qatar, 2005.

16. Tavlas, G.S., The New Theory of Optimum Currency Areas, The World Economy. 16(6), pp.663-685, 1993.

17. Zaidi, I., Monetary Coordination among the Gulf Cooperation Council Countries, World Development, 18, pp.759-768, 1990. 